Article

\title{
Comparative Evolution of S7 Intron 1 and Ribosomal Internal Transcribed Spacer in Coilia nasus (Clupeiformes: Engraulidae)
}

\author{
Dong Liu, Hong-Yi Guo, Wen-Qiao Tang * and Jin-Quan Yang \\ College of Fisheries and Life Science, Shanghai Ocean University, Shanghai, 201306, China; \\ E-Mails: dliu@ shou.edu.cn (D.L.); hy-guo@ shou.edu.cn (H.-Y.G.); jqyang@ shou.edu.cn (J.-Q.Y.) \\ * Author to whom correspondence should be addressed; E-Mail: wqtang@ shou.edu.cn; \\ Tel./Fax: +86-21-6190-0425.
}

Received: 21 October 2011; in revised form: 17 January 2012 / Accepted: 28 February 2012 /

Published: 7 March 2012

\begin{abstract}
Coilia nasus is widely distributed in the Yangtze River, the coastal waters of China, Korea and the Ariake Sound of Japan. Several ecotypes exist and this provides a useful model for the study of comparative diversity between molecular markers. Here we analyze and compare the nucleotide sequences between single-copy ribosomal protein S7 gene intron 1 ( rpS7) and multiple-copy ribosomal internal transcribed spacer 1 (ITS1) in this species to compare the phylogenetic signal of the two nuclear genes. Nucleotide substitutions among the two gene sequences and partial sequence of mitochondrial cytochrome c oxidase subunit I (COI) gene were also analyzed. A total of 115 clones for rpS7 and 122 clones for ITS1 were obtained from 37 specimens. The nucleotide sequence length is 741 to $743 \mathrm{bp}$ for $r p S 7$ and 334 to $348 \mathrm{bp}$ for ITS1. Intra- and inter-specimen variation in $r p S 7$ results from nucleotide substitution, while such variation in ITS1 is mainly due to different numbers of short base repeats. The content of $\mathrm{G}+\mathrm{C}$ is lower in $r p S 7(43.5 \%)$ than in ITS1 $(68.2 \%)$. Our results indicate that the proportion of the sequence variable sites is higher in $r p S 7$ (61) than in ITS1 (23); the informative parsimony of $r p S 7$ is evidently higher than that of ITS1 (26 vs. 2); the overall ratio between transitions and transversions in ITS1 is slightly lower than in $r p S 7$, but remarkably lower than in COI. These results suggest that $r p S 7$ is more suitable than ITS1 as a marker for genetic divergence of this group. Furthermore, gene flow is observed between the different geographic populations of $C$. nasus from the phylogeny of this species based on $r p S 7$, showing that $r p S 7$ has more evolutionary characteristics for understanding the processes of genomic evolution at the intraspecific level.
\end{abstract}


Keywords: ribosomal protein S7 gene; internal transcribed spacer; Coilia nasus; comparative evolution; phylogeny; concerted evolution

\section{Introduction}

Well-selected molecular markers are crucial for the identification and phylogenetic study of closely related species, and within species with different geographic distributions. Such markers can aid in understanding the processes of biological diversification. One useful marker is the $\operatorname{rpS7}$ (ribosomal protein S7) gene, which consists of six introns and seven exons [1]. The first two introns of rpS7 show a high rate of evolution, less base compositional bias, and a relatively low transition/transversion ratio. The evolutionary characteristics of this nuclear marker have been used for systematic studies at the subfamilial level in African electric fishes [2]. By providing more information in sequence variation than the second one, the first intron is widely used as a marker for molecular phylogeny in cyprinid fishes [3], cichlid fishes [4], and darter fish genus Etheostoma [5]. The rpS7 gene is a single-copy gene and the conserved stretches of DNA in its adjacent exons have been used to design primer pairs for amplification of the intronic regions in fish which are more likely to be variable [6]. The rpS7 gene coupling with other nuclear and mitochondrial genes has been used as markers to investigate molecular phylogeny in various organisms [2,4,7]. The mitochondrial genome is maternally inherited and thus does not permit the detection of historical hybridization events resulting from the sexually reproducing organisms. However, the rpS7 alleles have a biparental mode of inheritance, and the allelic recombination enables the detection of such events [8,9]. However, Keck et al. [7] reported that the rpS7 dataset lacked the resolution required to determine interspecific relationships of Nothonotus darters, but was more useful for characterizing intraspecific relationships. Guo et al. [10] found that $r p S 7$ has more informative parsimony than cty $b$ in sinipercid fishes, although little is known about the intraspecific diversity of the rpS7 gene.

Another widely used marker is the first ribosomal internal transcribed spacer (ITS1), which is one region of the ribosomal RNA (rRNA) gene. Multiple copies (100-500) of the rRNA gene cluster in tandem, and each transcription unit is composed of $18 \mathrm{~S}$ rRNA coding region, ITS1 region, 5.8S rRNA coding region, ITS2 region and 28S rRNA coding region [11]. The ITS1 region is one of the most variable parts of the genome, able to verify and align sequences according to the conserved parts of rRNAs. Therefore it is suitable for phylogenetic analyses of closely related species [12]. The polymorphism studies of ITS1 in various organisms indicate concerted evolution among the products of this gene duplication, a process of homogenization involving reciprocal and nonreciprocal recombination for ribosomal DNA within and between chromosomes [13,14]. It results in interspecific divergence and intraspecific similarity among each copy of ITS1 [13]. The hypothesis of concerted evolution has been demonstrated in Cicindela dorsalis [14], crayfish species [15] and brown trout Salmo trutta [16]. Recently, the putative secondary structure of ITS1 was successfully used for species identification, as well as phylogenetic reconstruction of taxonomic groups in plants, insects and animals [17-19]. 
The grenadier anchovy Coilia nasus is a small-to-moderate-sized fish, widely distributed in the Yangtze River, localized in the coastal waters of China, and Korea as well as the Ariake Sound of southwestern Japan [20]. Earlier morphological and ecological studies of the grenadier anchovy have indicated that it represents a species complex, composed of Coilia nasus, a species that displays homing behavior, a closely related species Coilia brachygnathus, and one subspecies Coilia nasus taihuensis [21]. The homing species is an anadromous fish. The sexually mature fish migrate for spawning from their oceanic habitat to the Yangtze River during the reproductive season (March to August). After reproduction, these fish and their progeny then migrate back to the ocean in September to November of the same year. The latter two species inhabit only freshwater. C. brachygnathus spawns and lives in the middle and lower reaches of the Yangtze River. C. nasus taihuensis is only found in Lake Taihu, a landlocked freshwater lake in China (Figure 1). C. brachygnathus can be distinguished morphologically from $C$. nasus by its relatively reduced upper jaw length. $C$. nasus taihuensis, on the other hand, is distinguished from C. nasus by its reduced number of vertebrae [20]. Recent studies suggest that $C$. nasus taihuensis and $C$. brachygnathus are indistinguishable from C. nasus based on mitochondrial sequence and otolith characters [22,23]. Now the subspecies and the related species are regarded as the ecological forms of $C$. nasus throughout its distribution [24]. These ecotypes of $C$. nasus have high genetic diversity on mitochondrial markers, but they show limited population genetic structure [25].

Figure 1. Map of the Coilia nasus collection sites. The numbers denote 1 as Yangtze estuary (YE), 2 as Jingjiang (JJ), 3 as Lake Taihu (TH), 4 as Wuhu (WH), 5 as Lake Poyang (PY), 6 as Xiangshan (XS), and 7 as Ariake Sound (AS).

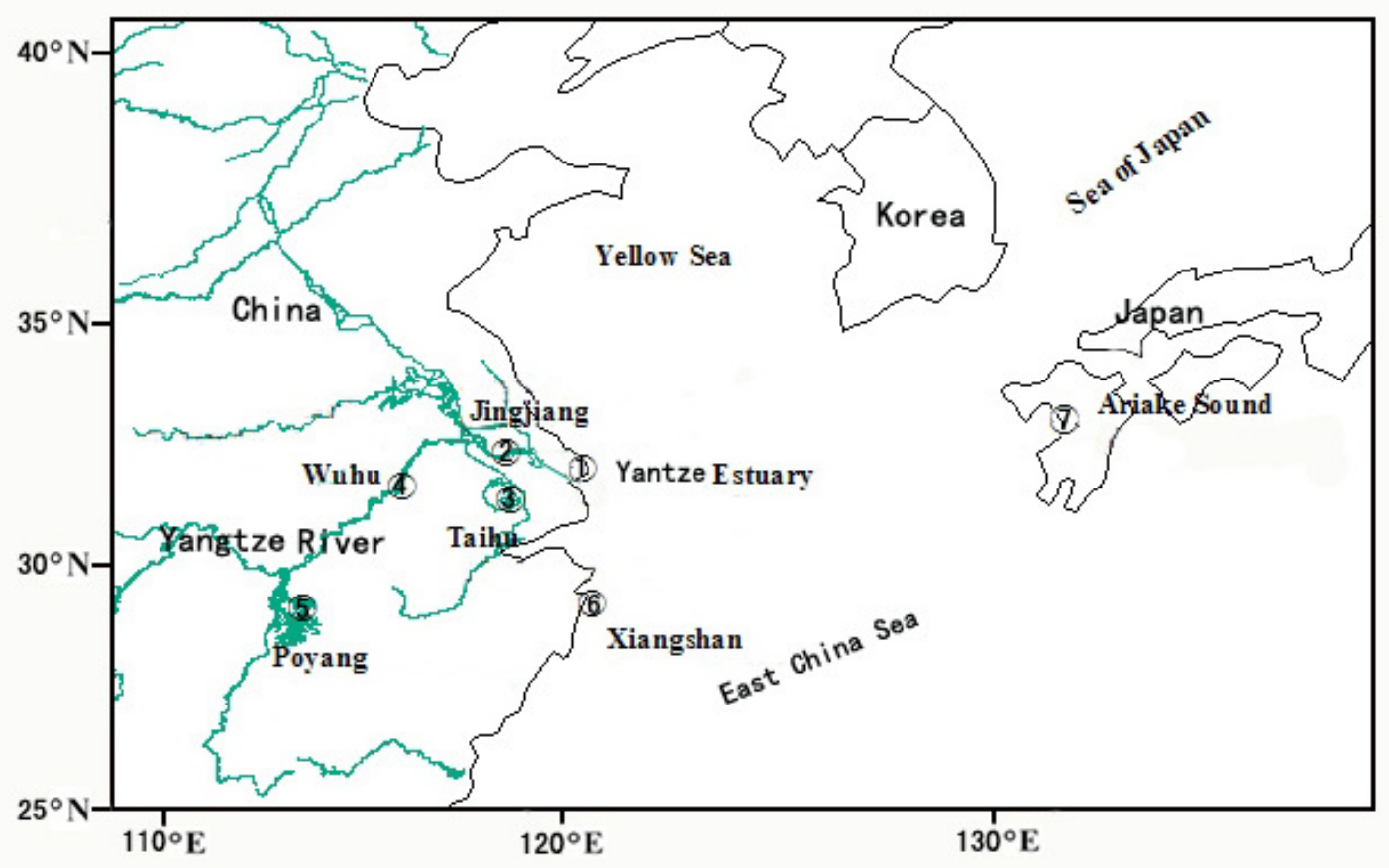

In this study, we have analyzed $r p S 7$ and ITS1 in 37 specimens of the grenadier anchovy C. nasus collected from seven geographical populations to investigate the sequence diversity and to compare evolutionary characteristics of the two ribosomal genes at the intraspecific level. In doing so, we 
selected a partial sequence of mitochondrial cytochrome c oxidase subunit I (COI) gene, the so-called "DNA barcode", as a standard for assessing the overall ratio between transitions and transversions of the nucleotide sequence. We selected COI for our analysis, also due to its widespread and successful utilization in discriminating sister species [26], hence we applied this approach to identify representative samples of the $C$. nasus complex. To our knowledge, the present study is the first report to compare molecular diversity between the single-copy gene $r p S 7$ and the multiple-copy gene ITS1 within species. Our results indicate that considerable intragenomic variability exists in $r p S 7$ due to mutation, while ITS1 contains different numbers of repeat motifs that occupy the internal loops of the putative secondary structure. Trees constructed with rpS7 show a stronger phylogenetic signal than ITS1 based on the $C$. nasus dataset, making $r p S 7$ a preferred choice for population studies in this species.

\section{Results and Discussion}

\subsection{Results}

\subsubsection{Composition and Variation of $r p S 7$ Intron 1}

A total of 115 rpS7 clones were sequenced for 37 C. nasus individuals from seven sampling sites (Figure 1), yielding intron fragments that were 741-743 bp long. In total 29 different haplotypes were identified. Sequences were deposited in GenBank under accession numbers JN394513-394541. Haplotype alignments and their frequencies were shown in Table 1. Their codes include the abbreviation of the locality names in Figure 1, then an Arabic numeral (which denoted the specimen number for each sampling site), and a lowercase numeral (in the cases where there were multiple haplotypes for each individual). One common haplotype (H29) was shared by eight clones (TH5a, YE3a, XS1a, XS2a, XS3, JJ6a, WH3 and AS), producing from these specimens sampling from six localities (TH, YE, XS, JJ, WH and AS). Three haplotypes (H12, H13 and H28) were encountered twice (PY3b and YE4; PY4 and YE3b; JJ6b and WH4). Ten out of the thirty-seven C. nasus individuals examined showed two different sequence types with variable positions (3-16), in which three individuals (PY3, TH6 and YE3) were found a 1-bp gaps and missing (Indel), and three individuals (TH1, XS1 and XS2) were observed a 2-bp Indel, and one individual (JJ5) was detected a 1-to 2-bp Indel (Table 1). Four of the individuals in our study displayed two alleles, which may have been the result of intraspecific hybridization events (Table 2). For example, position 52 was a putative parental allele, because (1) the $\mathrm{T}$ nucleotide was present in 21 clones from five individuals of $\mathrm{TH}$ population; (2) the A nucleotide was present in 25 clones from six individuals of PY population; (3) the heterozygosity of the two nucleotides were found in the individuals from JJ and SX populations. However, one concern of molecular variation at the intragenomic level is the reliability of the amplification reaction, in which DNA stretches leads to copying errors by Taq polymerase in a way analogous to the biological replication process [27]. In our study, these position nucleotides could not be errors produced by Taq enzyme, because nucleotide positions did not vary in fifteen clones from five individuals of the AS population; this population was an isolated one in comparison of the other six, could be regarded as ancestral parent (Table 2). The nucleotide compositions and variable information of 29 haplotypes were shown in Table 3. 
Table 1. Alignment, frequencies and haplotypes of rpS7 in Coilia nasus.

\begin{tabular}{|c|c|c|c|}
\hline \multirow{4}{*}{ Code } & Sequence & \multirow{4}{*}{ 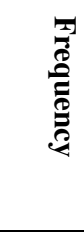 } & \multirow{4}{*}{ 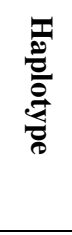 } \\
\hline & 00000000011111111122222222333333444444444445555555555555566666666677777 & & \\
\hline & 5555577880015568990113459934566912233668899000011233456900113344812234 & & \\
\hline & 2567856171930927561485444627616220556057938346907548233347461801121943 & & \\
\hline $\mathrm{JJ} 1 \mathrm{a}$ & TGTGGATTTTACTTCGACTTGTTAATTTACCCAAGATATACATTAGGATTGCTCTATACTAAACACTTGA & 2 & H1 \\
\hline $\mathrm{JJ} 1 \mathrm{~b}$ & $\mathrm{~A} A \ldots \mathrm{C} \ldots \mathrm{A} \ldots \mathrm{T} \ldots \ldots \mathrm{C} \ldots \mathrm{C} \ldots \ldots \mathrm{C} \cdot \mathrm{G} \ldots \mathrm{G} \cdot \mathrm{A} \ldots \ldots \mathrm{A} \cdot \mathrm{C} \ldots \ldots \mathrm{G} \ldots \mathrm{C}$ & 3 & $\mathrm{H} 2$ \\
\hline $\mathrm{JJ} 2 \mathrm{a}$ & $\ldots \ldots \mathrm{C} \ldots \ldots \ldots \ldots \ldots \mathrm{C} \ldots \mathrm{G} \ldots \ldots \ldots \ldots \ldots \ldots \ldots \ldots \ldots \ldots, \mathrm{C} \ldots \mathrm{C}$. & 1 & $\mathrm{H} 3$ \\
\hline $\mathrm{JJ} 2 \mathrm{~b}$ & 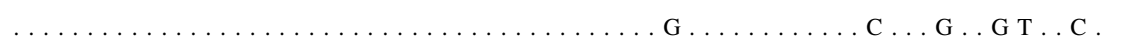 & 2 & $\mathrm{H} 4$ \\
\hline $\mathrm{JJ} 3$ & 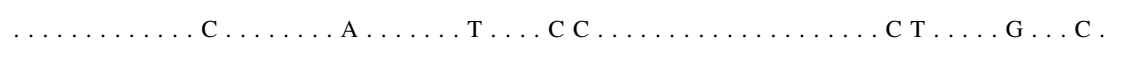 & 3 & H5 \\
\hline $\mathrm{JJ} 4$ & A A $\ldots$ C $\ldots$ A. T $\ldots \ldots \ldots$ C $\ldots \ldots$ C. G $\ldots$ G $. A-\ldots . T \ldots \ldots$ T G $\ldots$ C & 2 & H6 \\
\hline JJ5a & 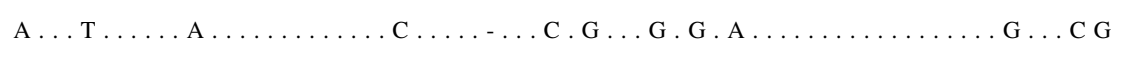 & 2 & $\mathrm{H} 7$ \\
\hline $\mathrm{JJ} 5 \mathrm{~b}$ & $\mathrm{~A} \mathrm{~A} \ldots \mathrm{C} \ldots \mathrm{A} \ldots \mathrm{T} \ldots \ldots \ldots \mathrm{C} \ldots \ldots \mathrm{C} \cdot \mathrm{G} \ldots \mathrm{G} \cdot \mathrm{A}-\mathrm{C} \ldots \mathrm{T} \ldots \ldots \mathrm{T}, \ldots \mathrm{C}$ & 2 & $\mathrm{H} 8$ \\
\hline PY1 & А $\ldots \mathrm{T} \ldots \ldots \mathrm{A} \ldots \ldots \ldots \mathrm{C} \ldots \ldots \mathrm{C} \cdot \mathrm{G} \ldots \mathrm{G} \cdot \mathrm{A} \ldots \ldots \mathrm{A} \ldots \ldots \mathrm{G} \ldots \mathrm{C}$ & 3 & H9 \\
\hline PY2 & 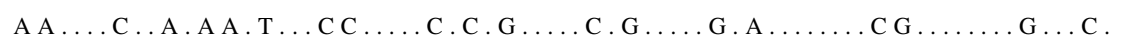 & 2 & H10 \\
\hline PY3a & $\mathrm{A} \ldots \mathrm{T} \ldots \mathrm{C} \ldots \mathrm{A} \ldots \ldots \ldots \ldots \mathrm{C} \ldots \ldots \ldots \mathrm{C} . \mathrm{G} \ldots \mathrm{C} \mathrm{G} . \mathrm{A} \ldots \ldots \ldots \ldots \ldots \mathrm{G} \ldots \mathrm{C}$ & 2 & H11 \\
\hline PY3b & $\mathrm{A} \ldots \mathrm{T} \ldots \ldots \mathrm{A} \ldots \ldots \ldots \mathrm{C} \ldots \ldots, \mathrm{C} \cdot \mathrm{G} \ldots \mathrm{G}, \mathrm{A} \ldots \ldots \ldots \ldots, \mathrm{G} \ldots \mathrm{C}$ & 5 & $\mathrm{H} 12$ \\
\hline PY4 & $\mathrm{A} \ldots \mathrm{T} \ldots \ldots \mathrm{A} \ldots \ldots \ldots \mathrm{C} \ldots \mathrm{C} \ldots \ldots \mathrm{C} \cdot \mathrm{G} \ldots \mathrm{G} \cdot \mathrm{A} \ldots \ldots \mathrm{A}, \mathrm{C} \ldots \mathrm{G} \ldots \mathrm{C}$ & 6 & H13 \\
\hline TH1a & $\ldots \ldots \ldots \ldots \ldots \mathrm{C} \ldots \ldots \mathrm{G} \ldots \mathrm{C}$. & 2 & H14 \\
\hline TH1b & $\ldots \ldots \ldots \mathrm{G} \ldots \ldots \ldots \ldots \ldots \ldots \ldots \ldots \ldots+\mathrm{T} \ldots \mathrm{C} \ldots \mathrm{G} \ldots \mathrm{G} \ldots \mathrm{C}$ & 1 & H15 \\
\hline TH2 & (2. & 3 & H16 \\
\hline TH3 & 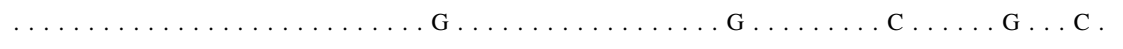 & 3 & H17 \\
\hline TH4 & $\ldots \ldots \ldots \mathrm{C} \ldots \ldots \mathrm{G} \ldots \mathrm{C}$. & 5 & H18 \\
\hline TH5b & $\ldots \ldots$ C. G $\ldots \ldots \ldots$ T $\ldots \ldots \ldots \ldots$ G T $\ldots \ldots \ldots \ldots$ C $\ldots$ G $\ldots$ C & 2 & H19 \\
\hline TH6a & $\ldots \mathrm{C} \mathrm{T} \ldots \mathrm{G} \ldots \mathrm{C}$ & 3 & $\mathrm{H} 20$ \\
\hline TH6b &. $\mathrm{C} \ldots \ldots \ldots \mathrm{C} \ldots \mathrm{C} \ldots \ldots \ldots \mathrm{A} \ldots \ldots \mathrm{C} \mathrm{T} \ldots \mathrm{G} \ldots \mathrm{C}$. & 2 & $\mathrm{H} 21$ \\
\hline YE1 & $\mathrm{A} A \ldots \mathrm{C} \ldots \mathrm{A} \ldots \mathrm{T} \ldots \ldots \mathrm{C} \ldots \mathrm{G} \ldots \mathrm{C} \cdot \mathrm{G} \ldots \mathrm{G} \cdot \mathrm{A} \ldots \ldots \mathrm{C} \ldots \ldots \mathrm{G} \ldots \mathrm{C}$ & 3 & $\mathrm{H} 22$ \\
\hline YE2 & $\mathrm{A} A \ldots \mathrm{C} \ldots \mathrm{AA} \cdot \mathrm{T} \ldots \ldots \mathrm{C} \ldots \mathrm{G} \ldots \mathrm{C} \cdot \mathrm{G} \ldots \mathrm{G} \cdot \mathrm{A} \ldots \ldots \mathrm{C} \ldots \ldots \mathrm{G} \ldots \mathrm{C}$ & 3 & $\mathrm{H} 23$ \\
\hline XS1b & $\mathrm{A} \ldots \ldots \ldots \mathrm{A} \ldots \ldots \ldots \mathrm{C} \ldots \ldots \mathrm{G} \ldots \mathrm{C} \ldots \ldots \ldots \ldots \ldots \mathrm{C} \ldots \ldots \ldots \mathrm{C}$ & 2 & $\mathrm{H} 24$ \\
\hline $\mathrm{XS} 2 \mathrm{~b}$ & 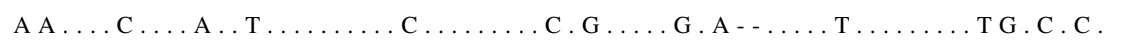 & 2 & $\mathrm{H} 25$ \\
\hline WH1 & A A $\ldots$ C $\ldots$ A. T $\ldots \ldots \ldots$ A $\ldots \ldots$ G. C. G $\ldots$ G. A $\ldots \ldots \ldots \ldots$ G $\ldots$ C & 3 & $\mathrm{H} 26$ \\
\hline WH2 & А А $\ldots$ C $\ldots$ A. T $\ldots \ldots \ldots$ C $\ldots$ G $\ldots$ T C $. G \ldots G . A \ldots \ldots \ldots \ldots$ G $\ldots$ C & 3 & $\mathrm{H} 27$ \\
\hline WH4 & $\mathrm{A} \ldots \ldots \ldots \mathrm{A} \ldots \ldots \ldots \mathrm{C} \ldots \ldots \mathrm{G} \ldots \mathrm{C} \ldots \ldots \ldots \ldots \ldots \ldots \mathrm{C} \ldots \ldots \mathrm{G} \ldots \ldots$ & 6 & $\mathrm{H} 28$ \\
\hline AS & $\ldots \ldots \ldots \ldots \mathrm{C} \ldots \ldots \mathrm{G} \ldots \mathrm{C}$. & 15 & $\mathrm{H} 29$ \\
\hline
\end{tabular}

Table 2. The representative specimens fixed in hybrid genotypes from the putative parental sequences at four nucleotide positions in $r p S 7$.

\begin{tabular}{lllcccc}
\hline & Position & & $\mathbf{5 2}$ & $\mathbf{1 1 3}$ & $\mathbf{2 9 6}$ & $\mathbf{4 3 5}$ \\
\hline \multirow{2}{*}{ Parent } & $\mathrm{AS}(5) *$ & & $\mathrm{~T}$ & $\mathrm{C}$ & $\mathrm{T}$ & $\mathrm{A}$ \\
& $\mathrm{TH}(5)^{*}$ & & $\mathrm{~T}$ & $\mathrm{C}$ & $\mathrm{T}$ & $\mathrm{A}$ \\
& \multirow{2}{*}{ JJ1 } & $\mathrm{a}$ & $\mathrm{T}$ & $\mathrm{C}$ & $\mathrm{T}$ & $\mathrm{A}$ \\
\multirow{2}{*}{ Hybrid } & $\mathrm{b}$ & $\mathrm{A}$ & $\mathrm{A}$ & $\mathrm{C}$ & $\mathrm{C}$ \\
& \multirow{2}{*}{$\mathrm{JJ6}$} & $\mathrm{a}$ & $\mathrm{T}$ & $\mathrm{C}$ & $\mathrm{T}$ & $\mathrm{A}$ \\
& & $\mathrm{b}$ & $\mathrm{A}$ & $\mathrm{A}$ & $\mathrm{C}$ & $\mathrm{C}$ \\
\hline
\end{tabular}


Table 2. Cont.

\begin{tabular}{lllllll}
\hline \multirow{4}{*}{ Hybrid } & XS1 & $\mathrm{a}$ & $\mathrm{T}$ & $\mathrm{C}$ & $\mathrm{T}$ & $\mathrm{A}$ \\
& & $\mathrm{b}$ & $\mathrm{A}$ & $\mathrm{A}$ & $\mathrm{C}$ & $\mathrm{C}$ \\
PS2 & $\mathrm{a}$ & $\mathrm{T}$ & $\mathrm{C}$ & $\mathrm{T}$ & $\mathrm{A}$ \\
Parent & $\mathrm{PY}(6) *$ & $\mathrm{~b}$ & $\mathrm{~A}$ & $\mathrm{~A}$ & $\mathrm{C}$ & $\mathrm{C}$ \\
* The bracketed figure indicates the number of specimens. The lowercase stands for the different genotype at \\
nucleotide positions from the same specimen.
\end{tabular}

Table 3. Summary statistics of rpS7, ITS1 and COI in Coilia nasus.

\begin{tabular}{|c|c|c|c|c|c|c|c|c|c|}
\hline & \multicolumn{2}{|c|}{$\begin{array}{c}\text { Nucleotide } \\
\text { Composition (\%) }\end{array}$} & \multicolumn{3}{|c|}{ Variable Sites } & \multicolumn{2}{|c|}{ Haplotypes } & \multicolumn{2}{|c|}{ AMOVA $(\%)$} \\
\hline & $\mathrm{A}+\mathrm{T}$ & $\mathrm{G}+\mathrm{C}$ & single & parsi & indel & $\mathrm{H}$ & $\mathrm{Hd}$ & among & within \\
\hline$r p S 7$ & 56.5 & 43.5 & 35 & 26 & 9 & 29 & 0.76 & 29.9 & 70.1 \\
\hline ITS1 & 31.8 & 68.2 & 21 & 2 & 18 & 29 & 0.69 & 10.3 & 89.7 \\
\hline \multirow[t]{3}{*}{$\mathrm{COI}$} & 55.5 & 45.5 & 4 & 6 & 0 & 9 & 0.68 & 1.9 & 98.1 \\
\hline & \multicolumn{2}{|c|}{ Nucleotide Diversity } & \multicolumn{3}{|c|}{ Trans/Transv } & \multicolumn{4}{|c|}{ Neutrality Tests } \\
\hline & among & within & $\mathrm{s}$ & $\mathrm{v}$ & $\mathrm{s} / \mathrm{v}$ & Taj D & $P *$ & $\mathrm{Fu}$ & $P^{*}$ \\
\hline$r p S 7$ & $0.013-0.017$ & 0.013 & 45 & 16 & 2.8 & -1.328 & $\mathrm{~N}$ & -2.377 & $\mathrm{~N}$ \\
\hline ITS1 & $0.003-0.009$ & 0.006 & 16 & 9 & 1.8 & -2.263 & $\mathrm{Y}$ & -2.377 & $\mathrm{~N}$ \\
\hline $\mathrm{COI}$ & $0.001-0.005$ & 0.003 & 8 & 2 & 4.0 & -1.070 & $\mathrm{~N}$ & -1.018 & $\mathrm{~N}$ \\
\hline
\end{tabular}

$P *$ denotes statistical significance $(P<0.05)$.

Testing nucleotide recombination detected three recombination positions $\left(R_{\mathrm{m}}=3\right)$, and analysis of nucleotide heterogeneity indicated that three clones (JJ1a, PY2 and TH1a) were possibly involved recombination events $(P<0.05)$. These putative recombination events were omitted from the following analysis. The average ML distance was 0.014 for the overall population. Specimens from four populations (JJ, YE, XS and $\mathrm{WH}$ ) that traditionally represent $C$. nasus were treated as a compound population (CP). The ML distance between PY and TH/AS was 0.016/0.014, while the highest ML distance of 0.017 between $\mathrm{CP}$ and TH was more than four times that of the lowest distance between TH and AS (0.004); this suggests that TH and AS populations were entirely isolated populations. Analysis of nucleotide diversity among populations showed that the value between JJ and TH was the highest, and that between PY and TH was the lowest (Table 3). Statistical testing of the $r p S 7$ neutrality gave values of -1.328 (Tajima's D) and $-2.377(\mathrm{Fu})$, although there was no significant difference $(P>0.1$ for each). AMOVA, neutrality tests, and the rate of the nucleotide substitution were described in Table 3. Nucleotide substitution favored transitions over transversions, and the relative rate of nucleotide substitution was 2.8 (Table 3). A plot of transitions and transversions versus genetic distance showed that the index of substitution saturation (ISS) was 0.0173 , ISS < ISS.C (critical value 0.7474), and the interpretation result was significantly different. Therefore, it can be concluded that the $r p S 7$ gene did not reach saturation, and this gene dataset can be used to restructure the phylogenetic relationship of the $C$. nasus complex. 


\subsubsection{Compositional Information of ITS1}

For each of the 37 C. nasus individuals 3-6 clones (total 122 clones) were isolated and sequenced, which produced 29 haplotypes. Sequences were deposited in GenBank under accession numbers JN394484-3944512. One common haplotype was encountered in all seven populations (frequency $=29.5 \%$ ). Excluding rRNA coding regions, the aligned ITS1 sequence of $C$. nasus ranged from 334 to $348 \mathrm{bp}$. Overall, the number of variable positions was low (Table 3). Two parsimony positions (75: T/C and 76: T/G) were found between individuals PY3 and WH1 (These codes referred to that of rpS7 mentioned above), and also within individuals. For some individuals, 2-4 different clones were observed, and the sequences of the clones differed by at least one position. Two types of tandem repeat, a 2-bp (CT) repeat and a 5-bp (CCAAA) repeat (Table 4), were detected to be variable for duplicated numbers within inter- and intra-individual, resulting in the variability of ITS1 in length. Tests of base homogeneity were congruent. Base pair composition, positions of nucleotide variability, and rate of transitions and transversions were shown in Table 3. The relative rate of nucleotide substitutions was 2.1 (Figure 3). AMOVA showed that nucleotide diversity within populations $(89.7 \%$ ) was significantly higher than that between populations (10.3\%) (Table 3).

Table 4. Types and positions of the repeat motifs for ITS1 in Coilia nasus.

\begin{tabular}{ccc}
\hline Repeats & Sequence Position & Region of Secondary Structure \\
\hline$(\mathrm{CT})_{5-8} \mathrm{CC}(\mathrm{CT})_{3}$ & $96-121$ & 4th internal loop \\
$(\mathrm{CT})_{8}$ & $96-111$ & 4 th internal loop \\
$(\mathrm{CCAAA})_{1-2}$ & $281-297$ & 2 th internal loop \\
\hline
\end{tabular}

The ITS1 RNA secondary structure featured eight hairpin loops, one lateral loop and six internal loops (abbreviated IL) (data not shown, and folding temperature was fixed at $37{ }^{\circ} \mathrm{C}$, initial $\Delta \mathrm{G}=-166.30 \mathrm{kcal} / \mathrm{mol}$ ). The shortest stem in the structure was $4 \mathrm{bp}$, while the longest stem was $22 \mathrm{bp}$. Approximately $80 \%$ of ITS1 nucleotides were involved in the formation of hairpin loops. By comparing the secondary structure and the primary aligned sequences, it revealed variations for mostly indel sites on the IL-2 and IL-4 regions. A 5-bp repeat was duplicated in the IL-2 region, and different numbers of a 2-bp repeat were found in the IL-4 region (Table 4); these repeats resulted in the variation of ITS1 length. 15 out of 23 variable positions were found in loop regions (including hairpin, lateral and internal loops), and eight were found in the stem regions where four were compensating base changes ( $\mathrm{CBCs}$ ). The variation in the primary sequence of the stem region did not disturb the base pairs, suggesting $\mathrm{CBCs}$ in the stem regions must be frequent to maintain functionality in the secondary structures.

\subsubsection{Phylogenetic Analysis of $r p S 7$ Gene}

The genus Coilia composed of three species in China, C. nasus, C. grayii and C. mystus [20]. By utilizing the complete control region sequence of mitochondrial DNA (mtDNA) to investigate phylogenetic relationships of this group, C. grayii was found to be the sister group to $C$. nasus, and C. mystus occurred in the root of the phylogenetic tree [25]. Hence, $C$. grayii was used as a potential outgroup in this study. A phylogenetic tree of $C$. nasus was obtained from the rpS7 dataset by MEGA 
5.0 with Maximum-likelihood (ML) analysis (Figure 2). The tree was supported by the bootstrap test $(\geq 50 \%)$. In the tree presented in Figure 2, the haplotypes of $r p S 7$ formed two major clades. Clade A was divided into two subclades. The larger subclade included the migratory (JJ) and landlocked freshwater ecotypes (TH); the small subclade included the migratory (WH) and marine ecotypes (XS). Clade B consists of two subclades. One subclade composed of freshwater (PY) and migratory ecotypes (JJ); the other subclade showed a complex of marine (XS) and migratory ecotypes (YE, JJ and WH). It was worth noting that the subclade in clade A composed of XS1b and WH4; according to the two facts, (1) one common haplotype (H28) was shared by WH4 and JJ6b (Table 1); and (2) XS1 and JJ6 have a varying nucleotide at four positions (Table 2); hence the subclade showing putatively gene flow could be potentially detected by the $r p S 7$ phylogenetic tree.

Figure 2. The Maximum-likelihood tree resulted from $r p S 7$ intron 1 sequence. Numbers beside the nodes stand for bootstrap values from 1000 replicates. The abbreviations represent site, including TH (Lake Taihu), JJ (Jingjiang), AS (Ariake Sound), XS (Xiangshan), WH (Wuhu), YE (Yangtze estuary), and PY (Lake Poyang). Arabic numerals denote specimen number, and lowercases indicate haplotyes per individual. Coilia grayii was used as an outgroup.

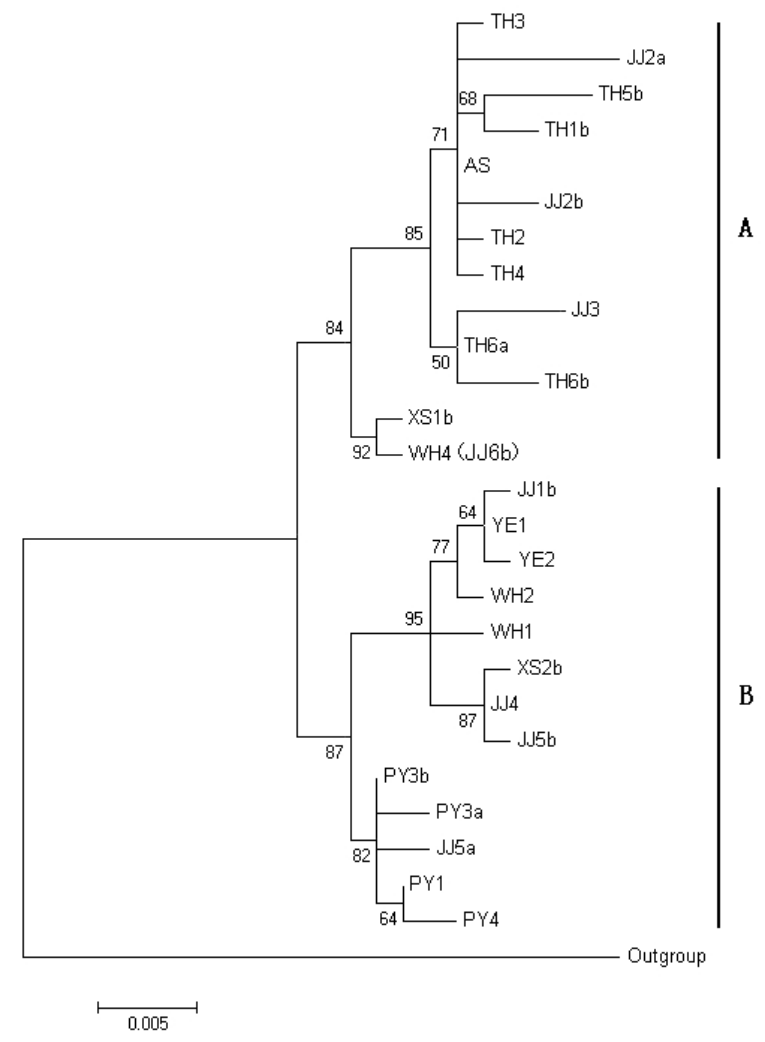

\subsubsection{Mitochondrial COI Molecular Variety}

The mitochondrial barcode derived from COI is regarded as a standard reference of diversity in DNA sequence. This marker has been used extensively for species identification. COI fragments of 652 bp in length were sequenced for 37 C. nasus individuals - a total of 9 haplotypes were detected. Their sequences have been deposited into GenBank (JN394472-394480). The base composition, etc. 
were described in Table 3. The average K2P distance-based COI was $0.2-0.4 \%$ (intrapopulation) and $0.1-0.5 \%$ (interpopulation). If the specimens of $C$. brachygnathus and $C$. nasus taihuensis were identified according to the previous morphological standard [21], and the representative specimens were treated either as separate species/subspecies or as single species, then the average K2P distance was $0.2-0.4 \%$ (intraspecies) and $0.3-0.6 \%$ (interspecies). These results revealed that the value of molecular divergence in $C$. nasus was far lower than the $2 \%$ sequence divergence that represents congeneric species of fish [28]. When datasets of COI, ITS1 and rpS7 from C. nasus were compared, the number of parsimony informative sites of the first two (6 and 2, respectively) was significantly lower than the latter (26); the nucleotide diversity of COI (0.003) was roughly equal to that of ITS1 (0.006), but both them were evidently lower than that of $r p S 7$ (0.013) (Table 3). When the relative rate of nucleotide substitutions (transitions/ transversions) among the three genes was compared, ITS1 was slightly lower than $r p S 7$, but remarkably lower than COI (Figure 3). These results indicate that $r p S 7$ have more sequence diversity than ITS1 or COI, and the nuclear $r p S 7$ marker could be phylogenetic utility of this group at intraspecific level.

Figure 3. The relative rates of nucleotide substitution for nuclear and mitochondrial genes in Coilia nasus.

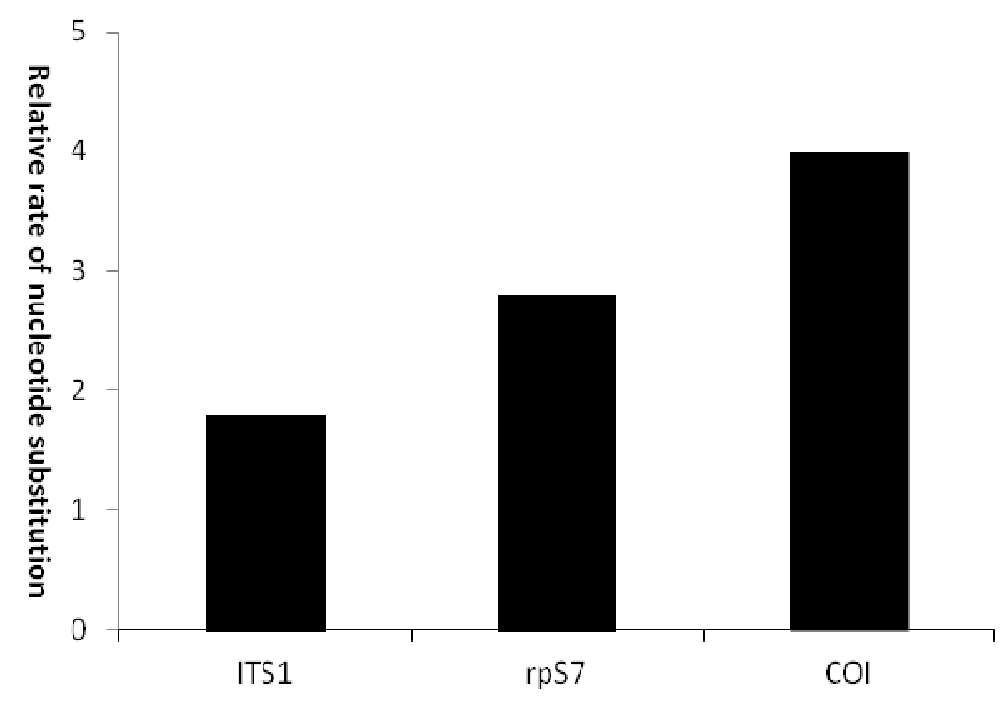

\subsection{Discussion}

The C. nasus complex exhibits morphological and ecological divergence across its natural distribution, and represents an ideal model in which to investigate the intraspecies diversity of nuclear sequences for rpS7 and ITS1. According to our study on 812 specimens covering the entire species complex of $C$. nasus collected from the middle and lower regions of the Yangtze River, local populations could be distinguished from one another on the basis of morphological characters such as maxillary length, vertebrae number and anal fin ray number, although identification characters have overlapped in some specimens [29]. The first 648 bp of COI has been widely used as a DNA barcode, an approach that has proven particularly useful for discriminating 5000 sibling species [26]. The COI sequence of $C$. nasus indicates the molecular divergence at the level of species does not reach the threshold of $2 \%$ that represents sibling species [28], thus the representative specimens covering the 
C. nasus complex from several populations provide a comparative clue for the divergence of $r p S 7$ and ITS1 at the intraspecific level.

The length of rpS7 in C. nasus is around $700 \mathrm{bp}$, which is similar to other fish, e.g., Sinipercid fish [10] and Notothenioid fish [30]. The length of the aligned ITS1 gene in C. nasus is about $350 \mathrm{bp}$, shorter than that of Salvelinus fish (596 bp) [31] and Salmo trutta (582 bp) [16]. The numbers of parsimony positions in ITS1 was lower (2) than in rpS7 (26), indicating that the divergence rate of the sequences differed between the two nuclear genes; furthermore, the results of the nucleotide diversity analysis and the value for transitions proportional to transversions also supported this hypothesis (Table 3). In other studies, the first intron of rpS7 gene is $719 \mathrm{bp}$ long, of which 168 positions are parsimony informative in 40 mormyroid species [2]; ITS1 from six species of the salmonid fish genus Salvelinus is 596 bp long, in which 45 are informative sites based on six sequence alignments [31]. For the intraspecies variation of ITS1 among 86 brown trout individuals by DNA directly sequencing, only 16 informative parsimony sites are found [16].

The evolutionary characteristics of the single-copy nuclear $r p S 7$ gene are a model of biparental inheritance [2], and the putative hybridization between parents could potentially be detected with parsimony information of rpS7 [9]. In our surveyed populations, rpS7 has aided in the potential detection of hybridization events. The putatively intraspecific hybrid individuals, i.e., JJ1, JJ6, XS1 and XS2 are polymorphic at four positions of $r p S 7$, while the contributing parents (TH and PY) show fixedly single nucleotide differences at these four sites (Table 2). The conclusion from morphologically characteristic data is that the putative hybrid specimens possess an intermediate upper jaw length between TH and PY specimens [29]. In addition, TH and AS samples maybe represent two potentially ancestral parents because they are geographically isolated populations but share the same haplotypes. The two geographical populations were produced by climatic oscillations during the Pleistocene ice ages [25]. Lake Taihu is adjacent to the Yangtze River, and TH population occasionally exchange with other geographical populations during flooding. In general, PY samples are characterized by reduced upper jaw length [20]. The Poyang Lake merges with the Yangtze River. It facilitates the intraspecific hybrid events to occur between PY population and other geographical populations. Therefore, intraspecific hybridization events might be occurring in $C$. nasus and such events could potentially be detected with rpS7. The high diversity of $r p S 7$ sequences within and between individuals is consistent with various phenotypes in the $C$. nasus complex from several populations. The greatest variation of $r p S 7$ in specimens from the middle and lower regions of the Yangtze River was due to recombination events; it is known that recombination can give more sequence divergence than mutation [32]. Our nucleotide sequence-based study provides evidence that the rpS7 could be used as a useful molecular marker for our study group.

In contrast, ITS1 indicates concerted evolution among the products of this gene duplication, resulting in interspecific divergence and intraspecific similarity among each copy [13]. The effects of concerted evolution usually impede the possibility to determine whether individuals are heterozygous or homozygous [33]. ITS1 shows concerted evolution and significantly low level of divergence among alleles in our study, and the varying number of repeat motifs results in different lengths of the ITS1 variants (334-348 bp). The considerable intragenomic variation in the number of repeat elements of ITS1 is enough to obscure phylogenetic relationships of crayfishes at the population level [15]. Nevertheless, the sequence divergence in ITS1 of tiger beetle Cicindela dorsalis shows that the 
variation within individual was almost as high as the variation within the entire lineage based on a total of 50 clones obtained from 12 specimens [14]. The repetitive ITS1 could provide genetic markers appropriate for population structure of scleractinian corals and sponges at inter- and intra-specific levels [33]. When ITS1 was used as a molecular marker for phylogeographic analysis of brown trout Salmo trutta, the results were congruent between both ITS1 and mtDNA [16]. Based on previously published data, it can be difficult to predict whether ITS1 will be suitable for phylogenetic analysis at the intraspecific level in a given taxon.

The intra- and inter-individual variation in $r p S 7$ could be seen to have occurred via nucleotide transitions and transversions, while the variation in ITS1 was mostly due to varying numbers of indels (Table 3). The relative rate of nucleotide substitutions in the rpS7 sequence was slightly higher than that of ITS1, but remarkably lower than that of COI (Figure 3). Similarly, the overall ratio between transitions and transversions in $r p S 7$ is lower than in $c y t b$ in Sinipercid fishes [10]. Comparison of the populations found that the molecular variance in ITS1 was $\sim$ three times lower $(10.3 \%)$ than that of rpS7 (29.9\%) (Table 3). The results demonstrate the concerted evolution of ITS1, similar to the lower evolutionary rates for ITS1 reported in brown trout Salmo trutta [16] and truffle Terfezia terfezioides [34]. Although different numbers of repeat elements producing sequence differences were encountered in ITS1 within and between individuals (Table 4), these repeat elements were observed in the internal loops of the predicted secondary structures, a major portion of the transcript in which the repeat element facilitates insertions and deletions by a slipped-strand mispairing mechanism [35]. Various patterns of repeat motifs have been published [13-15], yet to our knowledge, this is the first report of a "CT" repeat and different numbers of the repeat motif found in the internal loops that did not disturb functionality in the secondary structures.

The phylogenetic tree, restructured through maximum-likelihood method, was partially congruent with previous mtDNA analysis [25]. The samples from the four sites (PY, JJ, TH, and XS) grouped into two main lineages, but such lineages did not correlate with geographical populations based on the complete control region sequence of mtDNA [25]. In contrast, rpS7 was better able to resolve population relationships than mtDNA, e.g., all samples from TH, so-called C. nasus taihuensis, could be grouped into one subclade, and all samples from PY, so-called C. brachygnathus, formed another subclade, although the two subclades mixed the individuals sampled from other geographical populations. Furthermore, the proportion of the bootstrap values of the two major lineages was evidently higher in rpS7 (84\%) than in mtDNA (50\%). Interestingly, one subclade composed of XS1b and WH4 (Figure 2); the two haplotypes represent one of the varying genotypes, respectively (WH4 and JJ6b shared haplotype H28) (Table 2). Therefore, this subclade has potentially aided in the detection of a putative gene flow. This result indicates that gene flow maybe occurs among different ecotype of C. nasus, providing a clue for understanding the processes of its genomic evolution.

\section{Experimental Section}

\subsection{Sample Collection}

Specimens were collected from five sites from the middle and lower reaches of the Yangtze River, represented by the following codes: Yangtze estuary (YE), Jingjiang (JJ) in Jiangsu province, Wuhu 
(WH) in Anhui province, Lake Poyang (PY), and Lake Taihu (TH). Two further sites were Xiangshan harbor (XS) in the coastal region of the East Sea in China, and the Ariake Sound (AS) in Japan (Figure 1). C. nasus were sampled across the seven field sites, which enabled the inclusion of all ecotypes of this species. Specifically, YE, JJ, WH and PY samples represent the freshwater populations of either C. brachygnathus (collected in May to June) or C. nasus (collected in December to January); TH samples represent the landlocked ecotype of $C$. nasus taihuensis; XS samples represent the marine ecotype of $C$. nasus. The isolated AS samples were used as a reference. A total of 812 specimens collected from the seven sites were used to identify species according to the morphological characters [29], and 37 (5-6 from each site) were randomly chosen as representative samples, analyzed by DNA sequencing for $r p S 7$, ITS1, and COI genes. Muscle tissue that was used for molecular analysis was preserved in $95 \%$ ethanol, and the specimens were preserved in $70 \%$ ethanol and deposited in the Fish Collection of Shanghai Ocean University in China.

\subsection{DNA Extraction, PCR Amplification, Cloning, and Sequencing}

Total genomic DNA was extracted from small amounts of ethanol-preserved muscle by proteinase $\mathrm{K}$ digestion in lysis buffer at $55{ }^{\circ} \mathrm{C}$ for $2-3 \mathrm{~h}$, from the DNA extractor kit according to the manufacturers' instructions (Sangon, China). PCR primer sequences are listed in Table 5. Primer sequences for $r p S 7$ were obtained as described previously [6]. Primers for ITS1 and COI were designed using Primer Premier, version 5.0 [36], based on the sequences published in the National Centre for Biotechnology Information (NCBI) database. PCR reactions were performed in $50 \mu \mathrm{L}$ mixture contained $100 \mathrm{ng}$ of genomic DNA, $0.2 \mu \mathrm{M}$ of each primer, $50 \mu \mathrm{M}$ of each dNTPs, $5 \mu \mathrm{L}$ of $10 \times$ plus buffer, and $2 \mathrm{U} T a q$ plus polymerase (Tiangen, Beijing, China). PCR amplification was carried out in an Eppendorf Mastercycler (Eppendorf, Munich, Germany) as follows: $94{ }^{\circ} \mathrm{C}$ for $3 \mathrm{~min}$, and 30 cycles of $94{ }^{\circ} \mathrm{C}$ for $30 \mathrm{~s}, 58^{\circ} \mathrm{C}$ for $30 \mathrm{~s}\left(52{ }^{\circ} \mathrm{C}\right.$ for ITS $1,56{ }^{\circ} \mathrm{C}$ for COI), and $72{ }^{\circ} \mathrm{C}$ for $1 \mathrm{~min}$. A final extension was performed at $72{ }^{\circ} \mathrm{C}$ for $10 \mathrm{~min}$. Amplification products were separated, purified and transformed into E. coli DH5 $\alpha$ cells as described [13] except that the purified products of COI were directly sequenced. Positive clones were identified by blue/white screening. For sequence variation analysis at intraspecies level, 3-6 clones/specimen were randomly chosen and sequenced as described [13]. To be sure the sequence accuracy, all the clones were bidirectionally sequenced with vector-specific primers M13 and SP6 by an automated DNA sequencer (ABI PRISM 3730).

Table 5. PCR primers used for nuclear and mitochondrial data analysis.

\begin{tabular}{cccc}
\hline Primer & Gene & Sequence $\left(\mathbf{5}^{\prime} \mathbf{-} \mathbf{3}^{\prime}\right)$ & Source \\
\hline S7RPEX2R & $r p S 7-1$ & TGGCCTCTTCCTTGGCCGTC & Reference [6] \\
S7RPEX2R & $r p S 7-1$ & AACTCGTCTGGCTTTTCGCC & Reference [6] \\
ITS1F & ITS1 & AGGTGAACCTGCGGAAGG & Present study \\
ITS2R & ITS1 & TGATCCACCGCTAAGAGTTGTA & Present study \\
COIBF & COI & TGGCAATYACACGTTGATTYT & Present study \\
COIBR & COI & TTHCCBGCRTRRTARGCTACRA & Present study \\
\hline
\end{tabular}




\subsection{Molecular Data Analysis}

Sequence identity was confirmed based on the published sequences in the NCBI database. DNA sequences were aligned through a multiple sequence alignment with the ClustalX2 program, version 2.0 [37]. The ITS1 secondary structures were generated as described [38]. After structural elements were identified in the transcripts, the alignment was refined and screened for compensating base changes. The folding pattern of secondary structure elements was predicted on the web Mfold server as described [39]. Nucleotide composition, variable sites, position recombination, number of haplotypes and haplotype diversity were calculated using DnaSP software, version 5.10 [40]. MEGA software, version 5.0 [41] was used to calculate pairwise distances with the maximum composite likelihood method, the homogeneity of the base composition with the Id-test, the average Kimura 2 parameter (K2P) distance, and the relative rates of nucleotide substitution. Population genetic structure was evaluated by the analysis of molecular variance (AMOVA) method [42] using Arlequin, version 3.5 [43]. The possibility of substitution saturation was investigated by DAMBE software, version 5.2 [44] using the presence of nucleotide substitutions versus maximum likelihood distance. Neutrality of population genetic variation was estimated using Tajima's D and Fu's Fs statistical tests, both methods were implemented by the DnaSP software [40]. The arrays of phylogenetic analyses were performed by a maximum- likelihood approach in MEGA 5.0 [41]. The bootstrap values for the maximum likelihood tree were estimated using searches with 1000 replicates.

\section{Conclusions}

Results from this study are likely to represent the first data on comparison of different nuclear DNA markers $r p S 7$ and ITS1 for estimating intraspecific genetic diversity in genome of $C$. nasus. The rpS7 exhibits more phylogenetic signal than ITS1, and can be considered as a useful molecular marker required in detection of potentially intraspecific hybridization events, as well as for phylogenetic analysis of this taxon. In contrast, ITS1 shows a pattern of concerted evolution and sequence homogenization among the products of this gene duplication at intraspecific level.

\section{Acknowledgments}

We are very thankful to the anonymous referees for their useful comments on an earlier version of this manuscript. We want to thank Yingchun Xing, Xiaodu Zhou, Wanxiu Cheng and Guoli Zhu, studying at Shanghai Ocean University, for their help. This research was supported by Doctoral Discipline Foundation for Young Teachers in Higher Education Institutions of Ministry of Education (No. 20103104120001), Innovation Program of Shanghai Municipal Education Commission (No. \# 09YZ276; 12YZ132), National Natural Science Foundation of China (No. 31172407), Special Fund for Agro-scientific Research in the Public Interest (201203065), and Foundation for Hydrobiology Key Discipline Development of Shanghai (S30701).

\section{References}

1. Annilo, T.; Laan, M.; Stahl, J.; Metspalu, A. The human ribosomal protein S7-encoding gene: Isolation, structure and localization in 2p25. Gene 1995, 165, 297-302. 
2. Lavoue, S.; Sullivan, J.P.; Hopkins, C.D. Phylogenetic utility of the first two introns of the S7 ribosomal protein gene in African electric fishes (Mormyroidea: Teleostei) and congruence with other molecular markers. Biol. J. Linn. Soc. 2003, 78, 273-292.

3. He, S.P.; Mayden, R.L.; Wang, X.Z.; Wang, W.; Tang, K.L.; Chen, W.J.; Chen, Y.Y. Molecular phylogenetics of the family Cyprinidae (Actinopterygii: Cypriniformes) as evidenced by sequence variation in the first intron of S7 ribosomal protein-coding gene: Further evidence from a nuclear gene of the systematic chaos in the family. Mol. Phylogenet. Evol. 2008, 46, 818-829.

4. Musilová, Z.; Rícan, O.; Janko, K.; Novák, J. Molecular phylogeny and biogeography of the neotropical cichlid fish tribe Cichlasomatini (Teleostei: Cichlidae: Cichlasomatinae). Mol. Phylogenet. Evol. 2008, 46, 659-672.

5. Lang, N.J.; Mayden, R.L. Systematics of the subgenus Oligocephalus (Teleostei: Percidae: Etheostoma) with complete subgeneric sampling of the genus Etheostoma. Mol. Phylogenet. Evol. 2007, 43, 605-615.

6. Chow, S.; Hazama, K. Universal PCR primers for S7 ribosomal protein gene introns in fish. Mol. Ecol. 1998, 7, 1255-1256.

7. Keck, B.P.; Near, T.J. Assessing phylogenetic resolution among mitochondrial, nuclear, and morphological datasets in Nothonotus darters (Teleostei: Percidae). Mol. Phylogenet. Evol. 2008, 46, 708-720.

8. Costedoat, C.; Pech, N.; Chappaz, R.; Gilles, A. Novelties in hybrid zones: Crossroads between population genomic and ecological approaches. PLoS One 2007, 2, e357.

9. Yaakub, S.; Bellwood, D.; van Herwerden, L. A rare hybridization event in two common Caribbean wrasses (genus Halichoeres; family Labridae). Coral Reefs 2007, 26, 597-602.

10. Guo, X.; Chen, D. Comparative evolution of the mitochondrial cytochrome $b$ gene and nuclear $S 7$ ribosomal protein gene intron 1 in sinipercid fishes and their relatives. Hydrobiologia 2010, 649, 139-156.

11. Baffi, M.A.; Ceron, C.R. Molecular analysis of the rDNA ITS-1 intergenic spacer in Drosophila mulleri, D. arizonae, and their hybrids. Biochem. Genet. 2002, 40, 411-421.

12. Coleman, A.W.; Vacquier, V.D. Exploring the phylogenetic utility of ITS sequences for animals: A test case for abalone (Haliotis). J. Mol. Evol. 2002, 54, 246-257.

13. Bower, J.E.; Dowton, M.; Cooper, R.D.; Beebe, N.W. Intraspecific concerted evolution of the rDNA ITS1 in Anopheles farauti sensu stricto (Diptera: Culicidae) reveals recent patterns of population structure. J. Mol. Evol. 2008, 67, 397-411.

14. Vogler, A.P.; DeSalle, R. Evolution and phylogenetic information content of the ITS-1 region in the tiger beetle Cicindela dorsalis. Mol. Biol. Evol. 1994, 11, 393-405.

15. Harris, D.J.; Crandall, K.A. Intragenomic variation within ITS1 and ITS2 of freshwater crayfishes (Decapoda: Cambaridae): Implications for phylogenetic and microsatellite studies. Mol. Biol. Evol. 2000, 17, 284-291.

16. Presa, P.; Pardo, B.; Martinez, P.; Bernatchez, L. Phylogeographic congruence between mtDNA and rDNA ITS markers in brown trout. Mol. Biol. Evol. 2002, 19, 2161-2175.

17. Booton, G.C.; Kaufman, L.; Chandler, M.; Oguto-Ohwayo, R.; Duan, W.; Fuerst, P.A. Evolution of the ribosomal RNA internal transcribed spacer one (ITS-1) in cichlid fishes of the lake victoria region. Mol. Phylogenet. Evol. 1999, 11, 273-282. 
18. Liu, Z.; Chen, Z.; Pan, J.; Li, X.; Su, M.; Wang, L.; Li, H.; Liu, G. Phylogenetic relationships in Leymus (Poaceae: Triticeae) revealed by the nuclear ribosomal internal transcribed spacer and chloroplast trnL-F sequences. Mol. Phylogenet. Evol. 2008, 46, 278-289.

19. Yoon, H.S.; Lee, J.Y.; Boo, S.M.; Bhattacharya, D. Phylogeny of Alariaceae, Laminariaceae, and Lessoniaceae (Phaeophyceae) based on plastid-encoded RuBisCo spacer and nuclear-encoded ITS sequence comparisons. Mol. Phylogenet. Evol. 2001, 21, 231-243.

20. Whitehead, P.; Nelson, G.; Wongratana, T. FAO species catalogue. Clupeoid fishes of the world (Suborder Clupeoidei). Part 2. Engraulididae. FAO Fish. Synop. 1988, 125, 460-475.

21. Yuan, C.M.; Qing, A.L.; Liu, R.H.; Lin, J.B. Discussion on subspecific taxanomy of the genus Coillia in middle and lower reaches of Changjiang and southest coastal China Sea. J. Nanjing Univ. 1980, 3, 67-82.

22. Tang, W.Q.; Hu, X.L.; Yang, G.Q. Species validities of Coilia brachygnathus and C. nasus taihuensis based on sequence variations of complete mtDNA control region. Biodivers. Sci. 2007, 15, 224-231.

23. Guo, H.Y.; Wei, K.; Tang, W.Q.; Wu, J.M.; Chen, W.Y. Sibling species discrimination for Chinese genus of Coilia fishes based on sagittal otolith morphology. Acta Zootaxon. Sin. 2010, 35, 127-134.

24. Cheng, Q.Q.; Han, J.D. Morphological variations and discriminant analysis of two populations of Coilia ectenes. J. Lake Sci. 2004, 16, 356-364.

25. Yang, J.Q.; Hu, X.L.; Tang, W.Q. Genetic structure and population history of Coilia nasus in Yangtze River and its south adjacent waters. J. Shanghai Fish. Univ. 2008, 5, 513-519.

26. Ward, R.; Hanner, R.; Hebert, P. The campaign to DNA barcode all fishes, FISH-BOL. J. Fish Biol. 2009, 74, 329-356.

27. Bandelt, H.J.; Lahermo, P.; Richards, M.; Macaulay, V. Detecting errors in mtDNA data by phylogenetic analysis. Int. J. Legal Med. 2001, 115, 64-69.

28. Hebert, P.D.; Ratnasingham, S.; deWaard, J.R. Barcoding animal life: Cytochrome c oxidase subunit 1 divergences among closely related species. Proc. Biol. Sci. 2003, 270, S96-S99.

29. Cheng, W.X.; Tang, W.Q. Some phenotypic varieties between different ecotypes of Coilia nasus in Yangtze River. Chin. J. Zool. 2011, 46, 33-40.

30. Janko, K.; Lecointre, G.; DeVries, A.; Couloux, A.; Cruaud, C.; Marshall, C. Did glacial advances during the Pleistocene influence differently the demographic histories of benthic and pelagic Antarctic shelf fishes? CInferences from intraspecific mitochondrial and nuclear DNA sequence diversity. BMC Evol. Biol. 2007, 7, 220.

31. Pleyte, K.A.; Duncan, S.D.; Phillips, R.B. Evolutionary relationships of the salmonid fish genus Salvelinus inferred from DNA sequences of the first internal transcribed spacer (ITS 1) of ribosomal DNA. Mol. Phylogenet. Evol. 1992, 1, 223-230.

32. Hudson, R.R.; Kaplan, N.L. Statistical properties of the number of recombination events in the history of a sample of DNA sequences. Genetics 1985, 111, 147-164.

33. van Oppen, M.J.H; Wŏrheide, G.; Takabayashi, M. Nuclear Markers in Evolutionary and Population Genetic Studies of Scleractiniancorals and Sponges. In Proceedings 9th International Coral Reef Symposium, Bali, Indonesia, 23-27 October 2000; Indonesian Institute of Sciences: Jakarta, Indonesia, 2000; Volume 1; pp. 131-138. 
34. Kovacs, G.; Rudnoy, S.; Vagvolgyi, C.; Lasztity, D.; Racz, I.; Bratek, Z. Intraspecific invariability of the internal transcribed spacer region of rDNA of the truffle Terfezia terfezioides in Europe. Folia Microbiol. 2001, 46, 423-426.

35. Levinson, G.; Gutman, G.A. Slipped-strand mispairing: A major mechanism for DNA sequence evolution. Mol. Biol. Evol. 1987, 4, 203-221.

36. Lalitha, S. Primer premier 5. Biotechnol. Softw. Internet Rep. 2000, 1, 270-272.

37. Chenna, R.; Sugawara, H.; Koike, T.; Lopez, R.; Gibson, T.J.; Higgins, D.G.; Thompson, J.D. Multiple sequence alignment with the Clustal series of programs. Nucl. Acids Res. 2003, 31, 3497-3500.

38. Itskovich, V.; Gontcharov, A.; Masuda, Y.; Nohno, T.; Belikov, S.; Efremova, S.; Meixner, M.; Janussen, D. Ribosomal ITS sequences allow resolution of freshwater sponge phylogeny with alignments guided by secondary structure prediction. J. Mol. Evol. 2008, 67, 608-620.

39. Zuker, M. Mfold web server for nucleic acid folding and hybridization prediction. Nucl. Acids Res. 2003, 31, 3406-3415.

40. Rozas, J.; Sánchez-DelBarrio, J.C.; Messeguer, X.; Rozas, R. DnaSP, DNA polymorphism analyses by the coalescent and other methods. Bioinformatics 2003, 19, 2496-2497.

41. Tamura, K.; Peterson, D.; Peterson, N.; Stecher, G.; Nei, M.; Kumar, S. MEGA5: Molecular Evolutionary Genetics Analysis using Maximum Likelihood, Evolutionary Distance, and Maximum Parsimony Methods. Mol. Biol. Evol. 2011, 28, 2731-2739.

42. Excoffier, L.; Smouse, P.E.; Quattro, J.M. Analysis of molecular variance inferred from metric distances among DNA haplotypes: Application to human mitochondrial DNA restriction data. Genetics 1992, 131, 479-486.

43. Excoffier, L.; Lischer, H.E.L. Arlequin suite ver 3.5: A new series of programs to perform population genetics analyses under Linux and Windows. Mol. Ecol. Res. 2010, 10, 564-567.

44. Xia, X.; Xie, Z. DAMBE: software package for data analysis in molecular biology and evolution. J. Hered. 2001, 92, 371-373.

(C) 2012 by the authors; licensee MDPI, Basel, Switzerland. This article is an open access article distributed under the terms and conditions of the Creative Commons Attribution license (http://creativecommons.org/licenses/by/3.0/). 